\title{
Cyst-Like Osteolytic Formations in Recombinant Human Bone Morphogenetic Protein-2 (rhBMP-2) Augmented Sheep Spinal Fusion
}

Hsin Chuan Pan, ${ }^{*}$ Soonchul Lee, ${ }^{\dagger}$ Kang Ting, ${ }^{*}$ Jia Shen, ${ }^{*}$ Chenchao Wang, ${ }^{\ddagger} \Phi$ Alan Nguyen, ${ }^{*}$ Emily A. Berthiaume, Janette N. Zara, ${ }^{+\S \pi}$ A. Simon Turner, ${ }^{* *}$ Howard B. Seim, III, ${ }^{* *}$ Jin Hee Kwak, ${ }^{*}$ Xinli Zhang, ${ }^{*}$ and Chia Soo ${ }^{\ddagger \S \pi}$

\begin{abstract}
From the Dental and Craniofacial Research Institute and Section of Orthodontics, School of Dentistry, * UCLA Division of Plastic and Reconstructive Surgery, ${ }^{\ddagger}$ Department of Orthopaedic Surgery, ${ }^{\S}$ Orthopaedic Hospital Research Center, ${ }^{\uparrow}$ and David Geffen School of Medicine, $\|$ University of California, Los Angeles, Los Angeles, California; the Department of Orthopaedic Surgery, ${ }^{\dagger}$ CHA Bundang Medical Center, CHA University, Seongnam, Republic of Korea; and the Preclinical Surgical Research Laboratory, ** Department of Clinical Sciences, College of Veterinary Medicine, Colorado State University, Fort Collins, Colorado
\end{abstract}

\author{
Accepted for publication \\ March 30, 2017. \\ Address correspondence to \\ Xinli Zhang, M.D., Ph.D., CHS \\ 73-060, UCLA School of \\ Dentistry, 10833 Le Conte \\ Ave., Los Angeles, \\ CA 90095. E-mail: xzhang@ \\ dentistry.ucla.edu.
}

\begin{abstract}
Multiple case reports using recombinant human bone morphogenetic protein-2 (rhBMP-2) have reported complications. However, the local adverse effects of rhBMP-2 application are not well documented. In this report we show that, in addition to promoting lumbar spinal fusion through potent osteogenic effects, rhBMP-2 augmentation promotes local cyst-like osteolytic formations in sheep trabecular bones that have undergone anterior lumbar interbody fusion. Three months after operation, conventional computed tomography showed that the trabecular bones of the rhBMP-2 application groups could fuse, whereas no fusion was observed in the control group. Micro-computed tomography analysis revealed that the core implant area's bone volume fraction and bone mineral density increased proportionately with rhBMP-2 dose. Multiple cyst-like bone voids were observed in peri-implant areas when using rhBMP2 applications, and these sites showed significant bone mineral density decreases in relation to the unaffected regions. Biomechanically, these areas decreased in strength by $32 \%$ in comparison with noncystic areas. Histologically, rhBMP-2-affected void sites had an increased amount of fatty marrow, thinner trabecular bones, and significantly more adiponectin- and cathepsin K-positive cells. Despite promoting successful fusion, rhBMP-2 use in clinical applications may result in local adverse structural alterations and compromised biomechanical changes to the bone. (Am J Pathol 2017, 187: 1485-1495; http://dx.doi.org/10.1016/j.ajpath.2017.03.010)
\end{abstract}

Recombinant human bone morphogenetic protein-2 (rhBMP-2) has been recognized as an effective osteoinductive growth factor and has been found to induce bone regeneration in clinical trials and previous studies. ${ }^{1}$ Its capacity for limiting donor site morbidity and enhancing arthrodesis led to the US Food and Drug Administration (FDA) approving it for limited indication use in anterior lumbar interbody fusion, open tibial shaft fractures, and certain oral and maxillofacial uses. Consequently, the approved rhBMP-2 product, INFUSE Bone Graft (Medtronic, Memphis, TN), is produced in various doses. Many surgeons rapidly embraced this product, outside its indicated applications, for use in
Supported by California Institute for Regenerative Medicine Early Translational II Research Award TR2-01821 (K.T. and X.Z.); NIH/National Institute of Dental and Craniofacial Research grants R21 DE0177711 (C.S., K.T., and X.Z.) and RO1 DE16107-01 (C.S. and X.Z.); University of California Discovery grant 07-10677 (K.T., X.Z., and C.S.); Eli \& Edythe Broad Center of Regenerative Medicine and Stem Cell Research at UCLA Innovation Award (C.S., K.T., and X.Z.); and Korea Health Technology R\&D Project grant through the Korea Health Industry Development Institute and the National Research Foundation of Korea (NRF) grants HI16C1559 and 2016R1D1A1A02937040 (S.L.).

H.C.P., S.L., and K.T. contributed equally to this work.

X.Z. and C.S. contributed to this work equally as senior authors.

Disclosures: None declared. 


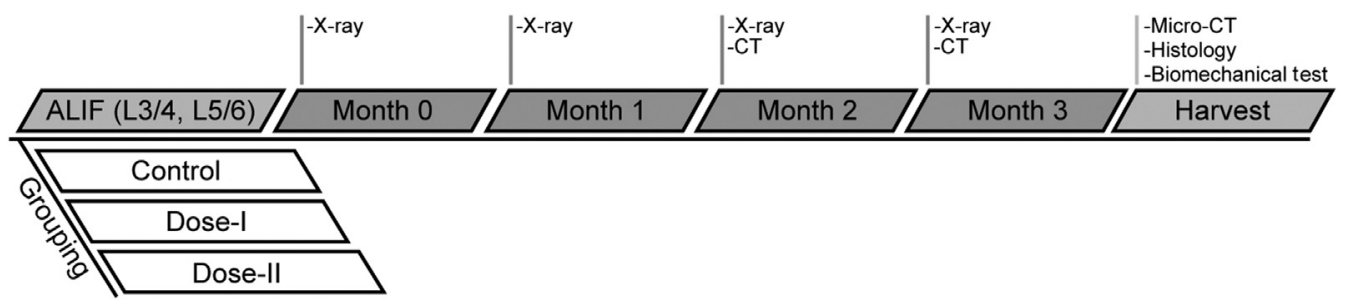

Figure 1 Experimental design. Spinal fusion (ALIF) operation was performed on animals randomly assigned to three different groupings. The analysis after the operation included monthly X-ray scans and conventional CT scans at months 2 and 3. At 3 months after the operation, samples were harvested and underwent high-resolution micro-CT, biomechanical, and histologic analyses. ALIF, anterior lumbar interbody fusion; CT, computed tomography; Dose-I, $0.43 \mathrm{mg} / \mathrm{mL}(0.65 \mathrm{mg}$ in total) recombinant human bone morphogenetic protein-2 and an absorbable collagen sponge in the spacer; Dose-II, $1.5 \mathrm{mg} / \mathrm{mL}$ (2.25 mg in total) recombinant human bone morphogenetic protein-2 and an absorbable collagen sponge in the spacer. $n=4$.

posterolateral fusions, transforaminal lumbar interbody fusions, and anterior cervical discectomy and fusions. ${ }^{2}$ Its use in these procedures lacks site-specific data and evidence for appropriate dosage, safety, or efficacy, but rhBMP-2 is still used for its favorable outcomes over autogenous bone graft procedures. ${ }^{2}$

Recently, researchers have reported adverse events associated with rhBMP-2, which range from cyst-like voids in developing bone, radiculopathy, retrograde ejaculation, and cancer. ${ }^{3-10}$ However, since gaining FDA approval, local adverse effects of rhBMP-2 have not been evaluated. Specifically, cyst-like bone voids in relevant spinal fusion models have yet to be reported. ${ }^{11}$ Recent advancements in imaging technology, such as high-resolution micro-computed tomography (micro-CT), permit exceptional micro-scale analysis of the bony structure to observe changes in bone structure induced by rhBMP-2, both quantitatively and qualitatively. We report that, despite its potent osteogenic effect, rhBMP-2 augmentation appears responsible for the osteolytic effects observed in local trabecular bone near the rhBMP-2 implants in sheep. The structural alterations in the affected bone, along with the aberration of biomechanical strength, are demonstrated and discussed for their clinical implications.

\section{Materials and Methods}

\section{Animals and Experimental Design}

The Colorado State University Institutional Animal Care and Use Committee approved all sheep surgical protocols. Six skeletally mature Rambouillet $\times$ Columbian ewes (Three JP, LLC livestock suppliers, La Junta, CO) underwent a twolevel anterior lumbar interbody fusion operation with radiolucent interbody vertebral spacers (Vertebral spacer-CR 889.915; Synthes, Monument, CO) fusion at two lumbar levels, L3 through L4 and L5 through L6. In total, 12 fusion sites were prepared. These levels were selected based on a prior study's findings. ${ }^{12}$ The radiolucent spacer was used to evaluate the longitudinal spinal fusion radiographically. The animals were divided into three groups; a control group receiving phosphate-buffered saline and an absorbable collagen sponge (ACS) in the spacer $(n=4)$, the dose-I group that received $0.43 \mathrm{mg} / \mathrm{mL}\left(0.65 \mathrm{mg}\right.$ in total $\left.^{13}\right)$
rhBMP-2 and an ACS in the spacer $(n=4)$, and a dose-II group that received $1.5 \mathrm{mg} / \mathrm{mL}\left(2.25 \mathrm{mg}\right.$ in $\left.\operatorname{total}^{14}\right)$ rhBMP-2 and an ACS in the spacer $(n=4)$. Dose-I of rhBMP-2 was based on the manufacturer's sheep study recommendation, and dose-II of rhBMP-2 was the FDA's approved dosage in humans. ${ }^{13,14}$ After the operation, X-rays and conventional CT were used to evaluate the fusions. Three months after the operation, the sheep were euthanized and L3-L4 and L5-L6 samples were assessed by micro-CT (H.C.P.), biomechanical (A.N.), and histologic (J.S. and X.Z.) analyses in a blinded fashion (Figure 1).

\section{Implant Preparation}

Before the operation, freeze-dried rhBMP-2 was reconstituted to 0.43 and $1.5 \mathrm{mg} / \mathrm{mL}$. rhBMP-2 solution $(1 \mathrm{~mL})$ was administered drop-wise onto a $2.5 \times 5 \mathrm{~cm}$ type I ACS (Helistat, Integrated Life Sciences, Plainsboro, NJ) and bound to the sponge for 30 minutes. The sponge was subsequently inserted into the cages.

\section{Surgical Procedures}

Ketamine was used before the operation as an analgesic. After anesthesia, the sheep were placed in a right lateral recumbent position. Access to L3 through L4 and L5 through L6 was made by a ventrolateral retroperitoneal approach, through the oblique abdominal muscles, to the plane ventral to the transverse processes. After identifying the L5-L6 disk space, an annulotomy was performed. The endplate was appropriately sized using a Midas-Rex burr. The disk space was opened with a vertebral spreader, and the cage (containing ACS with either phosphate-buffered saline or rhBMP-2) was inserted into the disk space. After the same procedure was performed at L3 through L4, each animal had two implantation sites. After implantation, the wound was closed, and cefazolin was injected to prevent infection.

\section{X-Ray and Conventional CT Imaging Acquisition and Analysis}

Anteroposterior and lateral view X-ray images were acquired immediately after the operation and at months 1,2 , 
and 3 after the operation. At 2 and 3 months after the operation, conventional $\mathrm{CT}$ images were taken at a slice thickness of $1.5 \mathrm{~mm}$, peak voltage of $130 \mathrm{kVp}$, and current of $175 \mu \mathrm{A}$, which resulted in a plane resolution of $0.35 \mathrm{~mm} /$ pixel per image. Successful spinal fusions were defined as $\geq 50 \%$ of a contiguous bone bridge area within the implant on conventional $\mathrm{CT}$, following the criteria from a previous report. ${ }^{15}$

\section{Micro-CT Imaging Acquisition and Analysis}

Three months after the operation, the sheep were euthanized by barbiturate overdose. The L3-L4 and L5-L6 spine segments were extracted and fixed in formaldehyde. Sample images were captured with a high-resolution micro-CT (SkyScan 1176 microCT; Bruker, Kontich, Belgium). Images were obtained at tube potential of $90 \mathrm{kVp}$ and $278 \mu \mathrm{A}$ with a $1-\mathrm{mm}$ copper filter set at a voxel size (resolution) of $18 \mu \mathrm{m}$. Three-dimensional reconstruction of the samples was obtained with NRecon software version 1.7.0.4 (Bruker).

For comprehensive image analysis, three distinctive volumes of interest (VOIs) were generated. VOI-1 (the core implant VOI) had a diameter and height of $7 \mathrm{~mm}$ and was centered in an anteroposterior position within the spacer relative to the cylindrical fusion site. It consisted of various concentrations of rhBMP-2 enclosed by the spacer. VOI-2 (the peri-implant VOI) was taken $7 \mathrm{~mm}$ above and below the implant spacer, which is an area associated with increased probability of materialized cyst-like osteolytic formations. The areas above and below the implant regions were separated into individual data sets. In all samples, the VOI range was determined after measuring the relative distance of bone quality changes from the center of the spacer. The volume was segmented following the spacer's contour to better examine the direct effect around the implant. VOI-3 (cyst-like bone void VOI) was generated to examine the cystic changes with greater precision. A standardized $27-\mathrm{mm}^{3}$ VOI was positioned in various osteolytic locations to analyze changes within the same sample. The bone volume fraction (bone volume/tissue volume), bone mineral density (BMD), and trabecular thickness (Tb.Th) were calculated at a threshold of 60 with CTAn software version 1.16.4.1 (Bruker).

\section{FEA}

Biomechanical strength was evaluated using finite element analysis (FEA). Micro-CT data were converted to DICOM images using NRecon software. Three-dimensional mesh models were subsequently generated from VOI-3, which enclosed the cystic change volume, to investigate precise mechanical changes. Model meshing was done with Mimics 3-Matics version 11.0 (Materialise, Leuven, Belgium), and FEA analysis was accomplished with ABAQUS version 6.14 (Dassault Systemes Simulia Corp., Warwick, RI).
Although the inferior bone surface was encastred as a boundary condition, a compressive stress of $0.5 \mathrm{MPa}$ was evenly applied to the superior surface, and the equivalent tensile stress experienced by each element was calculated.

\section{Histologic Analysis}

For histologic fixation, specimens were decalcified using $10 \% \mathrm{HCl}$ solution, washed under running tap water, and stored in $75 \%$ ethanol. Specimens were then embedded in paraffin and cut into 5-mm coronal sections. Hematoxylin and eosin and immunohistochemical staining were performed as previously described. ${ }^{16}$ Anti-cathepsin K (ab10927) and anti-adiponectin (ab62551) were used at a dilution of 1:100. The biotinylated anti-rabbit IgG secondary antibody (Dako North America, Inc., Carpinteria, CA) was used at a dilution of 1:200. Photomicrographs were acquired using Olympus BX51 $(\times 200$ magnification lens, UPLanFL; Olympus, Center Valley, PA) and SZX12 microscopes $(\times 8.4$ magnification lens, DF PLAPO $1.2 \times \mathrm{pf}$; Olympus).

\section{Statistical Analysis}

The means \pm SD of the data were calculated. Data were tested for normality using the Kolmogorov-Smirnov and Shapiro-Wilk tests. To test for significance between two groups, the $U$-test was used, whereas the Kruskal-Wallis test with post hoc Bonferroni tests was used when testing for significance between more than two groups. The statistical software SPSS version 18.0 (IBM, Armonk, NY) was used for all statistical analyses. Statistical significance was determined at $P<0.05$.

\section{Results}

Conventional CT Shows Improved Fusion and Cyst-Like Bone Void Lesions in Both rhBMP-2 Groups

After the operation, implanted spacer position was confirmed with X-ray imaging (Supplemental Figure S1). Conventional CT revealed that the control group did not demonstrate fusion in any of the sites, whereas both rhBMP2 groups were completely fused in all sites (100\%) $(P<0.05)$ (Figure 2). Bone volume fraction within the spacer was calculated and defined as a volumetric deformity when the bone volume fraction was $<90 \%$. The prevalence of volumetric deformities in the dose-I group was significantly higher than the other groups when imaged 2 months after the operation $(P<0.05)$. In all evaluation periods, radiolucent lesions, resembling possible osteolytic changes around the implant, were observed by conventional CT in both rhBMP-2 groups. However, because of the conventional CT's low resolution, the extent of the cyst-like bone voids was not quantifiable. Fusion qualities are summarized in Table 1. 

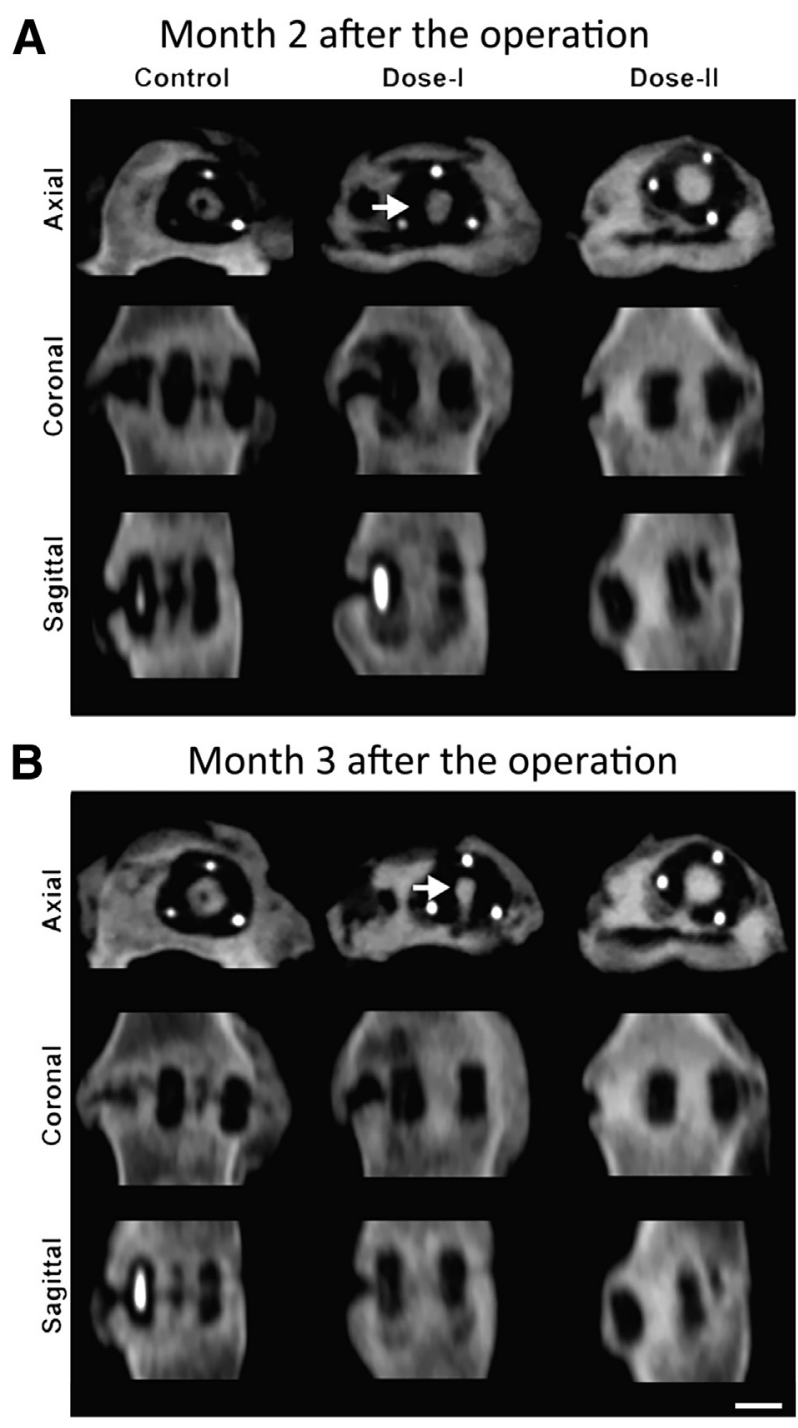

Figure 2 Results of conventional CT. A and B: Representative conventional CT images from each group 2 (A) and 3 (B) months after the operation. Successful fusion was observed in all rhBMP-2 groups, and no union was observed in the control group. The bone volume fraction within the spacer was calculated by measuring the ratio of new bone volume against the entire spacer volume at five vertical levels that were evenly distanced when positioned from an axial view. Volumetric deformity was defined as the bone volume fraction occupying $<90 \%$ of the spacer. In an axial view, a volumetric deformity of the implant core (arrow) was observed in the dose-I group at both time points. Scale bar $=5 \mathrm{~mm}$. CT, computed tomography; Dose-I, $0.43 \mathrm{mg} / \mathrm{mL}(0.65 \mathrm{mg}$ in total) rhBMP-2 and an absorbable collagen sponge in the spacer; Dose-II, $1.5 \mathrm{mg} / \mathrm{mL}(2.25 \mathrm{mg}$ in total) rhBMP-2 and an absorbable collagen sponge in the spacer; rhBMP-2, recombinant human bone morphogenetic protein-2.

Micro-CT Reveals Quantitative Volumetric Deformities of Newly Formed Bone inside the Spacer of rhBMP-2-Treated Samples

In axial and coronal micro-CT views, the control spines exhibited fragmented new bone growth within the implant, with new bone growth discontinuation at the center. In contrast, complete fusion of vertebrae through the center of the spacer was achieved in all dose-I and dose-II site samples (Figure 3, A and C). The volumetric deformity was better observed using micro-CT, which revealed that the dose-I group had a decreased new bone diameter $(5.919 \pm 1.311 \mathrm{~mm})$ compared with the other groups $(P<0.05)($ Table 1$)$.

\section{Micro-CT Demonstrates Dose-Dependent Increase of Bone Quality in Core Implant Area}

The dose-II core implant sites (VOI-1) exhibited significant increases in all variables (BMD, bone volume/tissue volume, Tb.Th) compared with the other groups $(P<0.01)$ (Figure 4A). In addition, denser bone was formed in the implant core area of both rhBMP-2 treatment groups (Figures $3 \mathrm{~A}$ and $4 \mathrm{~A}$ ). Despite a $100 \%$ fusion rate in both rhBMP-2 groups, VOI-2 did not demonstrate the same dosedependent trend shown in the core implant analysis. Dose-I had significantly lower BMD and Tb.Th than the control $(P<0.05$, in both) (Figure 4B).

\section{Cyst-Like Bone Void Areas Demonstrate Poor Bone Quality and Weakened Mechanical Strength}

Cyst-like bone voids were identified and localized after cross-referencing the micro-CT data sets with conventional CT, and especially in VOI-2 (Figure 4C). In both rhBMP-2 groups, the cyst-like bone voids were near the implant but varied in shape and size. These formations were not observed in the control group. The dose-I group showed a cluster distribution of smaller cyst-like bone voids above and below the implant spacer but not in the center region that directly contacted the concentrated implant site. In contrast, the cystic change in the dose-II group exhibited larger solitary bone voids. The bone volume fraction and BMD of VOI-3 were significantly decreased in relation to the unaffected regions in both rhBMP-2 groups (Figure 5). Biomechanical analysis using FEA further confirmed the micro-CT quantification, and all of the cyst-like bone void areas exhibited significantly increased stress levels, at 32\%, compared with the unaffected structures $(P<0.05)$ (Figure 6).

\section{Cyst-Like Bone Voids Are Attributed to Increased Adipogenesis and Osteoclastogenesis 0ccurring Near rhBMP-2 Implants}

Histologically, trabecular bone complete bony connectivity was observed in both rhBMP-2 treatment groups, whereas the cartilaginous tissue band in the middle of the implant's central area was observed only in the control group. Within the vicinity of the spacer surfaces, cyst-like bone void lesions were readily identifiable in the rhBMP-2 treatment groups (Figure 7, A-C). In both rhBMP-2 treatment groups, compared with the control group, the cyst-like bone 
Table 1 Fusion Quality Summary

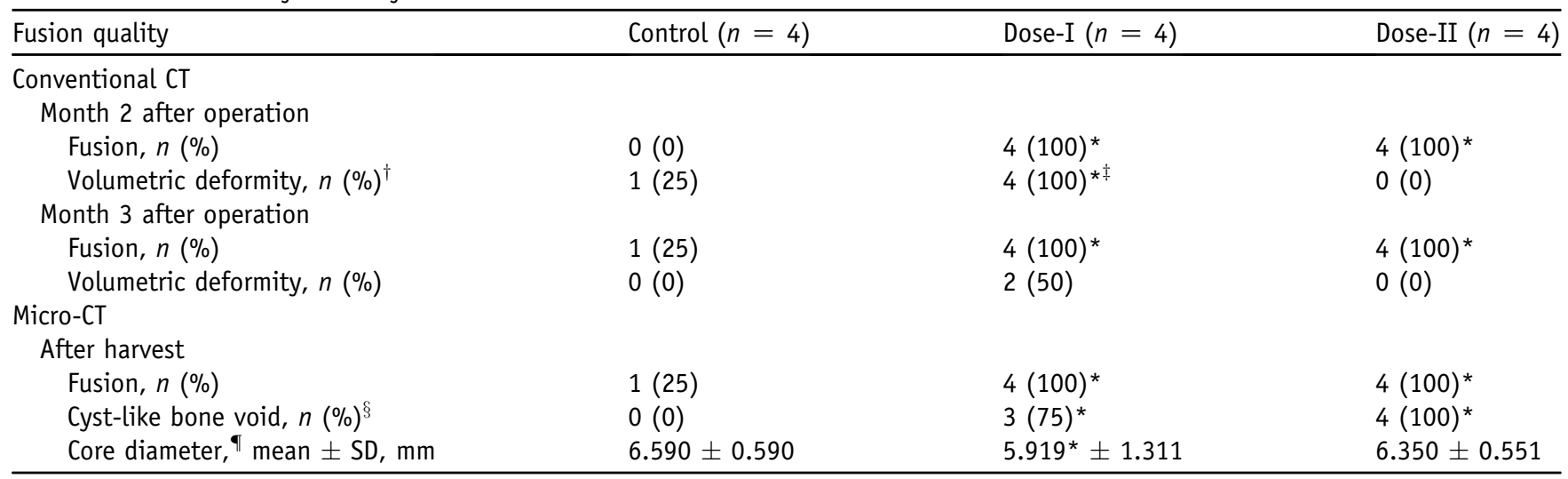

*Significant compared with control $(P<0.05)$.

'Decreased bone formation within the spacer compared with the core dimension.

Significant compared with dose-II $(P<0.05)$.

${ }^{\S}$ Cyst-like bone void indicates number of sample containing any number of cyst-like bone void lesions.

"Core diameter measurement taken at five vertical levels to measure circumferential changes at different levels inside the implants.

Dose-I, $0.43 \mathrm{mg} / \mathrm{mL}(0.65 \mathrm{mg}$ in total) recombinant human bone morphogenetic protein-2 and an absorbable collagen sponge in the spacer; Dose-II, $1.5 \mathrm{mg} / \mathrm{mL}$ (2.25 mg in total) recombinant human bone morphogenetic protein-2 and an absorbable collagen sponge in the spacer.

voids exhibited a thinner trabecular bone formation with larger cavities that were filled with fatty marrow (Figure 7, D-I). Notably, a focal lesion with inflammatory cells, dilated blood vessels, and a piece of dead bone were observed in the cyst-like bone voids of the dose-I group samples (Supplemental Figure S2A).

To further evaluate possible causes of the cyst-like bone voids in the rhBMP-2 samples, in situ expressions of representative adipogenesis protein markers, adiponectin, and osteoclastogenesis cathepsin $\mathrm{K}$, were detected by immunohistochemistry. The adiponectin-positive cells, a protein synthesized and secreted exclusively by mature adipose tissue and its progenitor cells, were abundant, with a higher adiponectin expression level in the rhBMP-2 groups than in the control group (Figure 8, A-C). Interestingly, there were two types of adiponectin-staining patterns that may reflect the phenotypic differences between the smaller progenitor cells and the mature fatty drop-filled adipocytes (Supplemental Figure S2B). Like adiponectin staining, more cathepsin K-positive osteoclasts were detected along the thinner trabecular bones in the rhBMP-2 groups (Figure 8, D-F). In addition, there were more cathepsin K-positive cells distributed within the marrow cavity in the rhBMP-2 samples. In general, this
A
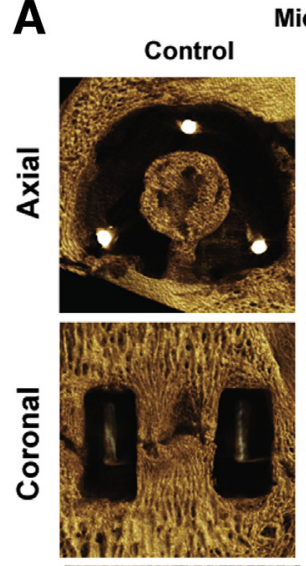

Micro-CT Reconstruction
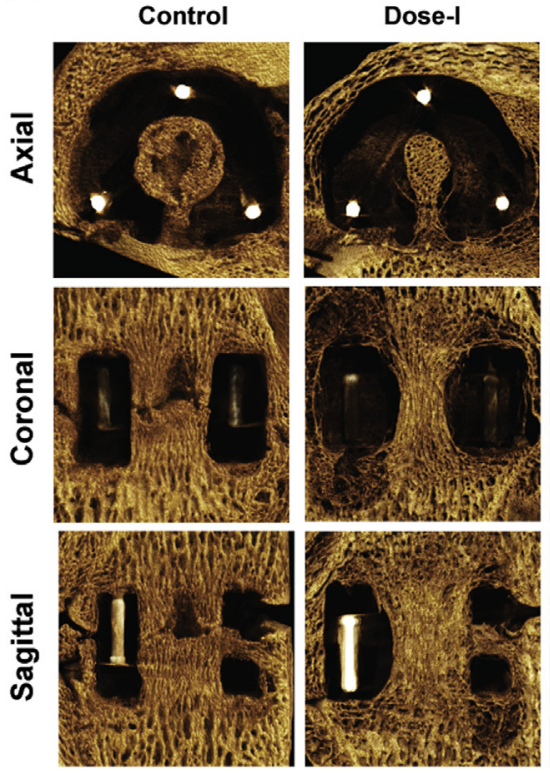

Dose-II
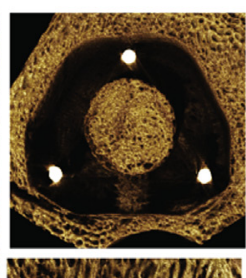

B 3D Section Locations

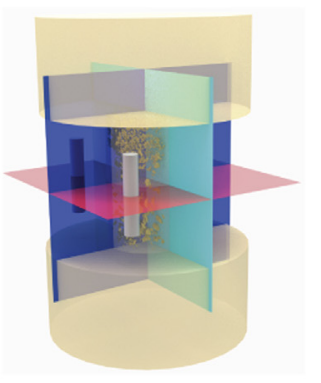

Axial

Coronal

Sagittal
Figure $33 \mathrm{D}$ orthogonal slice representatives from high-resolution micro-CT. A: The control group presented with a clear bony gap in all samples. Both rhBMP-2 groups showed solid fusion, but the dose-I group revealed a volumetric deformity toward the center. B: Axial view slice selection was based on the midpoint of the implant core's vertical dimension. Sagittal and coronal slices were determined from the center of the implant. Scale bar $=5 \mathrm{~mm} .3 \mathrm{D}$, three-dimensional; CT, computed tomography; Dose-I, $0.43 \mathrm{mg} / \mathrm{mL}(0.65 \mathrm{mg}$ in total) rhBMP-2 and an absorbable collagen sponge in the spacer; Dose-II, $1.5 \mathrm{mg} / \mathrm{mL}(2.25 \mathrm{mg}$ in total) rhBMP-2 and an absorbable collagen sponge in the spacer; rhBMP-2, recombinant human bone morphogenetic protein-2. 


\section{A Core implant}
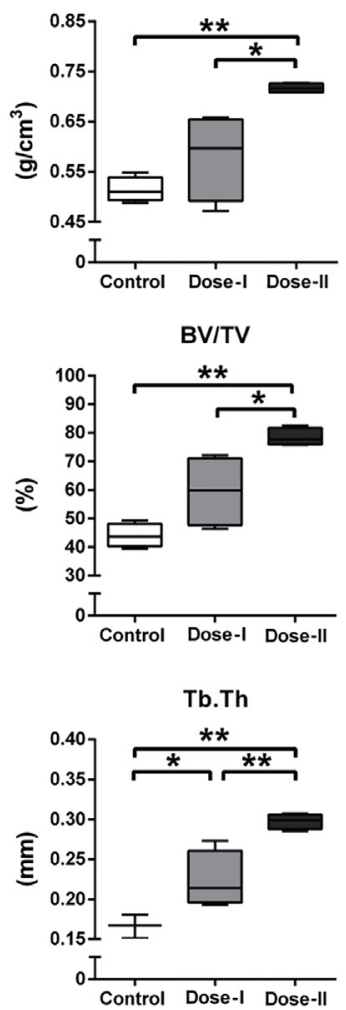

B Peri-implant BMD
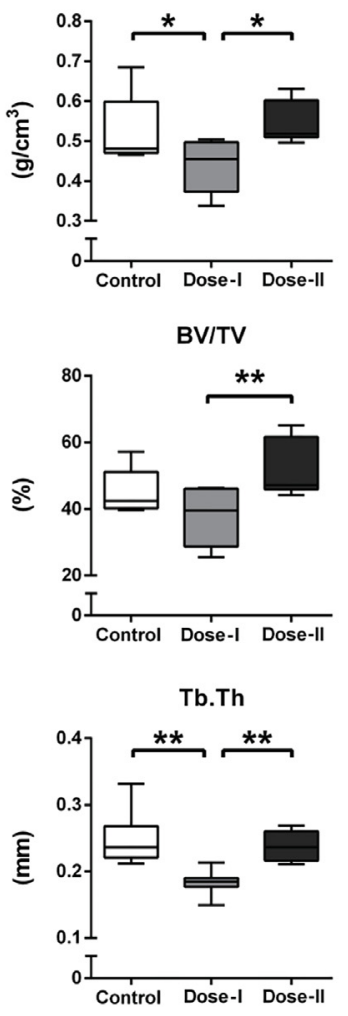

C Volume of interest

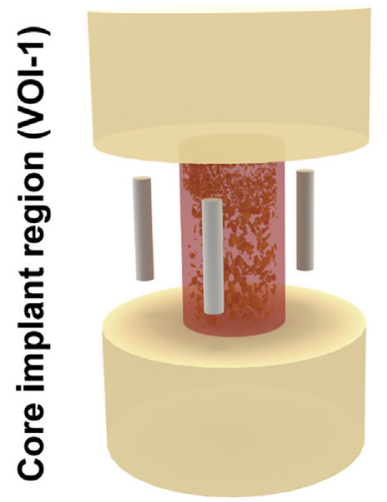

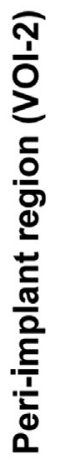

Figure 4 Quantitative analysis of fusion mass with high-resolution micro-CT. Fusion quality was quantitatively analyzed by dividing the sample into the core and peri-implant areas. A: The core area showed dosage-dependent BMD and BV/TV increases. B: The peri-implant area shows that the BMD was significantly lower in the dose-I group than in the control group. C: Core implant VOI-1 was defined as a cylindrical volume of $7 \mathrm{~mm}$ in height and diameter in the center of the spacer. Peri-implant VOI-2 was defined as the volume directly above and below the implant spacer, and following the spacer contour. The volume height was $7 \mathrm{~mm}$, because this was the furthest distance after comparing all samples in which cyst-like bone voids were observed. ${ }^{*} P<0.05,{ }^{*} P<0.01$. BMD, bone mineral density; BV/TV, bone volume/tissue volume; CT, computed tomography; Dose-I, $0.43 \mathrm{mg} / \mathrm{mL}(0.65 \mathrm{mg}$ in total) recombinant human bone morphogenetic protein-2 and an absorbable collagen sponge in the spacer; Dose-II, $1.5 \mathrm{mg} / \mathrm{mL}$ (2.25 mg in total) recombinant human bone morphogenetic protein-2 and an absorbable collagen sponge in the spacer; Tb.Th, trabecular thickness; VOI, volume of interest. may indicate the increased number of osteoclastic cells brought about by rhBMP-2 application. By including a negative staining control through replacing specific antibodies of adiponectin or cathepsin $\mathrm{K}$ with phosphatebuffered saline, the immunohistochemical-positive results appear to be antibody specific (Supplemental Figure S2C).

\section{Discussion}

Studies demonstrated that INFUSE Bone Graft had a positive effect on new bone formation and in healing existing bone by stimulating the recruitment and differentiation of bone-forming cells. ${ }^{17}$ In clinical practice, rhBMP-2 has been used as much as $85 \%$ for non-FDA-approved indications, including posterolateral fusion and transforaminal lumbar interbody fusions. ${ }^{18-25}$ The use of rhBMP-2 has elicited worrisome side effects, but no guidelines for dosage have

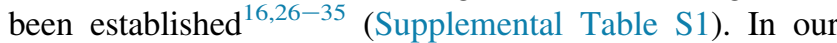
previous investigation that used a rodent model (H.C.P., S.L., K.T., J.S., C.W., A.N., E.A.B., J.N.Z., A.S.T., H.B.S., J.H.K., X.Z., and C.S., unpublished data), cyst-like bone voids were observed in rhBMP-2-assisted spinal fusions (Supplemental Figure S3). These findings necessitated the evaluation of fusion quality in larger animal models. Moreover, although several studies reported that the cyst-like bone voids were related to rhBMP-2 in both small $^{36}$ and large animal models, only conventional CT and histologic examination have been used for verification. ${ }^{37,38}$ Although lumbar interbody fusion is the most common indication for rhBMP-2, no prior study has comprehensively evaluated its use in the lumbar interbody fusion of a large animal model. Instead, its use has been widely documented in posterolateral fusions, vertebral body implantation, long bone metaphyseal defect, and radius segmental defect procedures. ${ }^{37-39}$

High doses of rhBMP-2 in spinal fusions, compared with the small amount of rhBMP-2 found in endogenous bone ( 2 to $30 \mu \mathrm{g} / \mathrm{kg}$ ), has been suggested as the main cause for the observed complications. ${ }^{20,40-45}$ Through simulating a large-animal study with comparable rhBMP-2 doses, the results suggest that the observed complications may also occur in human patients. Interestingly, the cyst-like bone voids were clearly observed in the peri-implant area (VOI2) of both rhBMP-2 groups. These groups also had significant decreases in bone quality, but no such lesions or changes in bone quality were detected in the control group. Despite having seemingly complete fusions, the dose-I group had a lower BMD and Tb.Th in the peri-implant area in comparison with the control. In the core implant area (VOI-1), the dose-I group had a higher bone volume fraction and BMD than the control group but still exhibited 


\section{A Control}
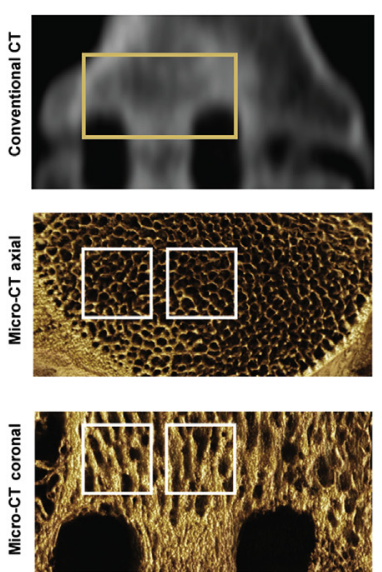

产

D

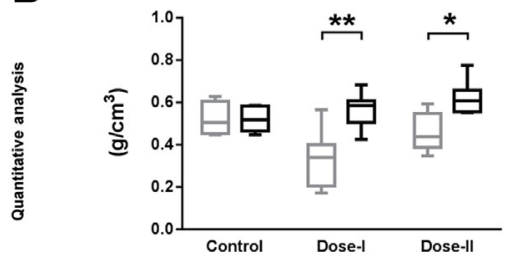

Cyst-like bone void lesion
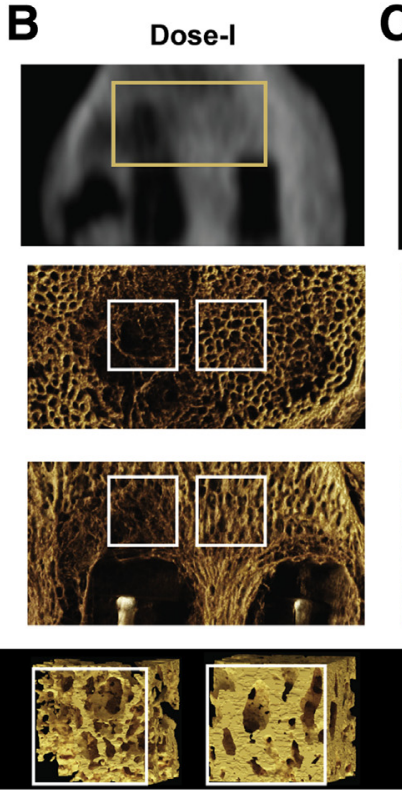

C
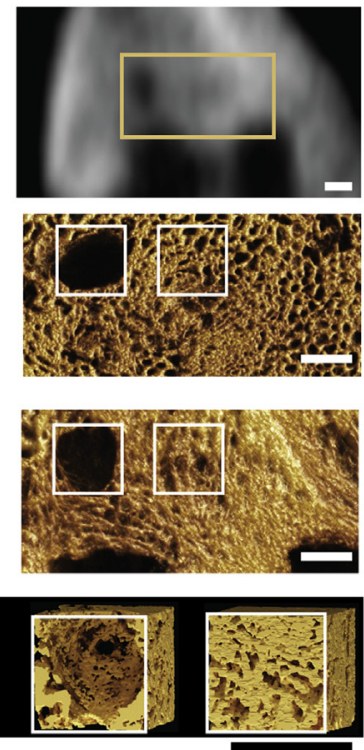

BV/TV

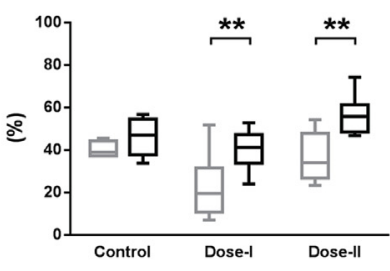

Noncystic bone void region

Figure 5 Representative images of cyst-like bone voids and quantitative analysis. From a macro to micro scale, the cyst-like bone void sites were analyzed. A: For the control, no cystic change was found throughout the sample. B and C: The dose-I group shows small clustered bone cysts over an area, whereas the dose-II group sample could localize as a solitary lesion. A $27-\mathrm{mm}^{3}$ VOI-3 was selected after reviewing all of the cyst-like bone void regions and was analyzed quantitatively to investigate the relative density/volume change. Orange boxed areas are locations where subsequent micro-CT illustrations (shown below) were extracted from, with white boxed areas depicting the $27-\mathrm{mm}^{3}$ cubic volumes used for analysis. D: The cubic volume was selected because of its relative position to the implant core, with one cubic volume directly above it and another more distant, but still adjacent to the spacer. The cystlike bone void area showed significant bone weakness (low BMD and BV/TV) compared with the unaffected sites. ${ }^{*} P<0.05,{ }^{*} P<0.01$. Scale bar $=3 \mathrm{~mm}$. BMD, bone mineral density; BV/TV, bone volume/tissue volume; $\mathrm{CT}$, computed tomography; Dose-I, $0.43 \mathrm{mg} / \mathrm{mL}(0.65 \mathrm{mg}$ in total) recombinant human bone morphogenetic protein2 and an absorbable collagen sponge in the spacer; Dose-II, $1.5 \mathrm{mg} / \mathrm{mL}$ (2.25 mg in total) recombinant human bone morphogenetic protein2 and an absorbable collagen sponge in the spacer; VOI, volume of interest.

an increased occurrence of volumetric deformities inside the spacer.

High-resolution micro-CT was chosen as the primary tool for analyzing alternations in bone structures because of its nondestructive preservation of tissue and field of view selection flexibility. ${ }^{46}$ With the use of the volumetrically reconstructed fused segment, we determined the exact location of cyst-like bone voids relative to the
A

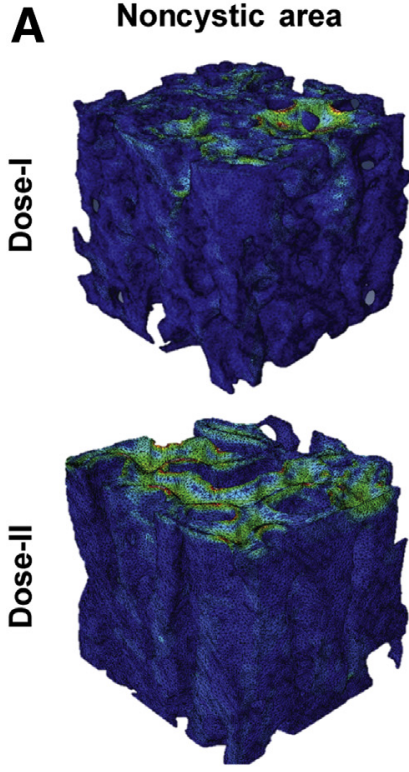

Cyst-like bone void
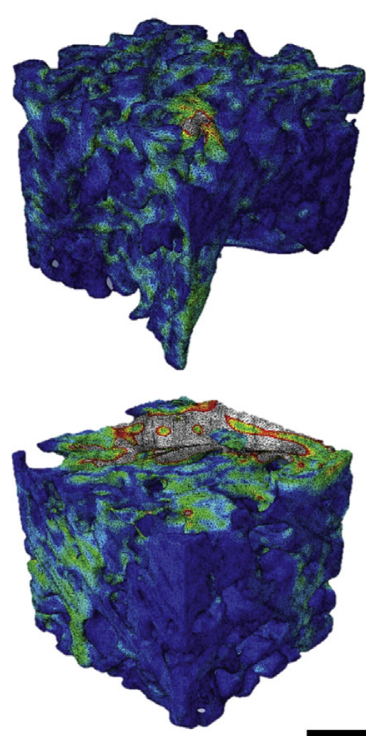

\section{B}

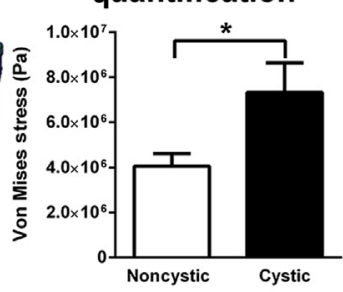

$\mathrm{S}$, Mises SNEG, (fraction $=-1.0$ ) (Avg: $75 \%$ )

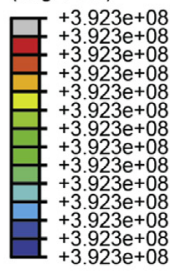

Figure 6 Biomechanical testing using FEA. A uniform compressive force of $0.5 \mathrm{MPa}$ was applied to the superior surface of the $27-\mathrm{mm}^{3}$ cubicshaped VOI of both noncystic and cyst-like bone void areas. A: Cuboidal specimens from cyst-like bone void area showed an increased von Mises stress with higher intensity of colors (gray regions indicate all values exceeding $25 \mathrm{MPa}$ ). B: Quantification of cuboidal segments of each sample bone demonstrated significantly increased von Mises stress in the cyst-like bone void, which suggested deteriorated bone strength. ${ }^{*} P<0.05$. Scale bar $=3 \mathrm{~mm}$. Dose-I, $0.43 \mathrm{mg} / \mathrm{mL}(0.65 \mathrm{mg}$ in total) recombinant human bone morphogenetic protein-2 and an absorbable collagen sponge in the spacer; Dose-II, $1.5 \mathrm{mg} / \mathrm{mL}$ (2.25 mg in total) recombinant human bone morphogenetic protein2 and an absorbable collagen sponge in the spacer; FEA, finite element analysis; $S$, Mises, von Mises stress; SNEG, surface negative; VOI, volume of interest. 


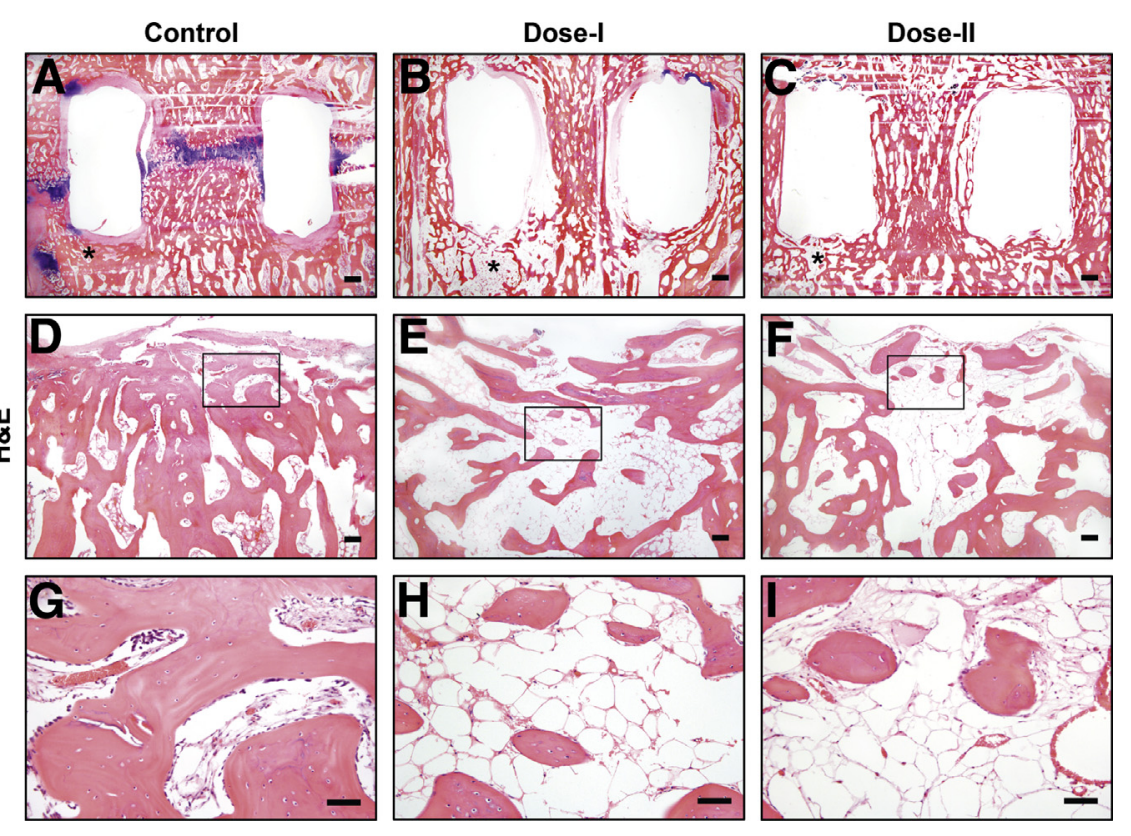

Figure 7 Histologic examination of cyst-like bone voids. A-C: The cyst-like bone voids were located immediately next to rhBMP-2 implants in both treatment groups as opposed to the control (asterisks). D-F: The expanded spaces that had fewer and thinner trabecular bones were seen in the cyst-like bone voids but not in the control sample. G-I: A profound amount of fatty marrow filled the cyst-like bone voids in both rhBMP-2 samples. D-F are magnified views from asterisk areas in $\mathbf{A}-\mathbf{C}$. The boxed areas in $\mathbf{D}-\mathbf{F}$ are shown below at higher magnification $(\mathbf{G}-\mathbf{I})$. Scale bars: 1 $\mathrm{mm}$ (top row); $200 \mu \mathrm{m}$ (middle row); $100 \mu \mathrm{m}$ (bottom row). Dose-I, $0.43 \mathrm{mg} / \mathrm{mL}(0.65 \mathrm{mg}$ in total) rhBMP-2 and an absorbable collagen sponge in the spacer; Dose-II, $1.5 \mathrm{mg} / \mathrm{mL}(2.25 \mathrm{mg}$ in total) rhBMP-2 and an absorbable collagen sponge in the spacer; $\mathrm{H} \& \mathrm{E}$, hematoxylin and eosin; rhBMP2 , recombinant human bone morphogenetic protein-2.

implant site. At the same time, through FEA, the detrimental effect of rhBMP-2 can be interpreted biomechanically, and the results alert potential users to clinical complications that could result in implant subsidence or fusion failure.

Several hypotheses were proposed for the cyst-like osteolytic formation mechanism, including osteolysis, adipocyte formation, and inflammation. Osteolysis, or bone resorption, is conceivably induced by rhBMP-2 increasing osteoclast cell activity ${ }^{5,14,47-51}$ through serine/ threonine receptors of BMP and the downstream molecules. In accordance with a previous report, ${ }^{52}$ we detected much more cathepsin K-positive cells in rhBMP-2 samples than in the control samples. Alternatively, BMP-2 and other BMPs are well-known up-regulators of adipogenesis by enhancing peroxisome proliferator-activated receptor- $\gamma$ signaling. ${ }^{53}$ Previous studies have shown that cyst-like bone voids with fatty marrow are observed with high doses of rhBMP-2 $(>150 \mathrm{mg} / \mathrm{mL}) .^{54}$ In this study, the fatty marrow profoundly filled the cyst-like bone voids between thinner trabecular bones. Adiponectin, a representative marker for adipogenesis, was readily detectable in both adipocytes and smaller progenitor cells throughout the fatty marrow in the rhBMP-2 samples, in contrast to fewer positive cells in the control sample. Finally, BMP's ability to induce inflammation appears essential to the in vivo osteoblastic signaling cascade. ${ }^{55}$ In mice, BMP has been shown to cause the release of key inflammatory cytokines, including tumor necrosis factor- $\alpha$, IL-1, and IL-6. ${ }^{8,55-57}$ However, overwhelming inflammation induced by high-dose rhBMP-2 can also contribute to cyst-like bone void development. ${ }^{58}$ Vertebral osteolysis after posterior lumbar interbody fusion may occur through the inflammatory effects of BMP, ${ }^{14}$ yet this likely did not happen in this study, because only a local inflammatory lesion was observed in the dose-I samples. Inflammatory
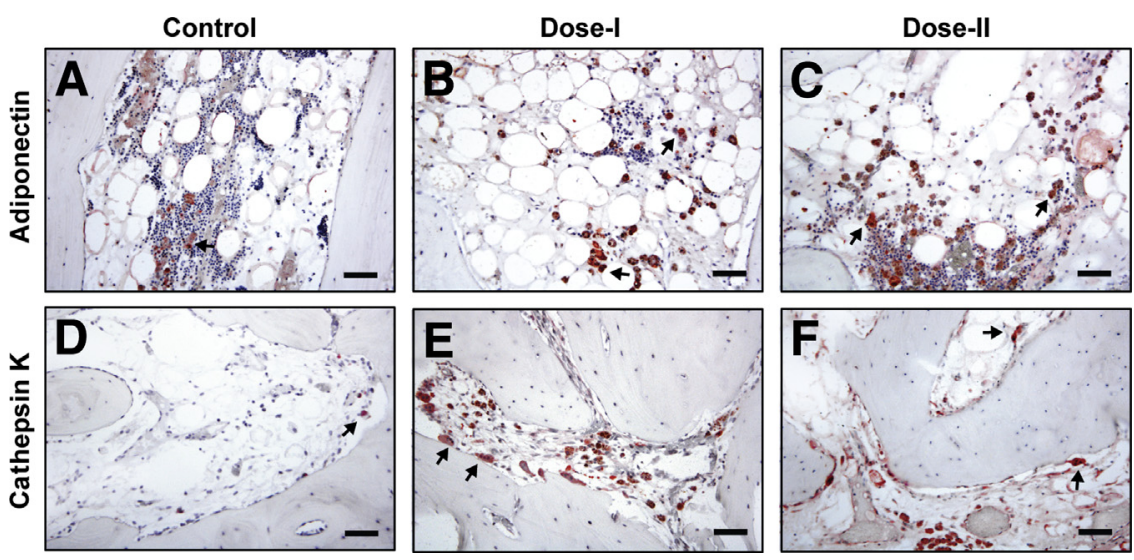

Figure 8 Immunohistochemistry of adiponectin and cathepsin K. A-C: Many more adiponectin-positive cells present in the marrow cavity were detected in the rhBMP-2 groups (arrows) than in the control sample (arrow). D-F: An increased number of cathepsin K-positive osteoclasts along trabecular bones and in marrow cavity were detected in the rhBMP2 groups (arrows) than in the control group (arrow). Scale bar $=100 \mu \mathrm{m}$. Dose-I, $0.43 \mathrm{mg} / \mathrm{mL}(0.65 \mathrm{mg}$ in total) rhBMP-2 and an absorbable collagen sponge in the spacer; Dose-II, $1.5 \mathrm{mg} / \mathrm{mL}(2.25 \mathrm{mg}$ in total) rhBMP-2 and an absorbable collagen sponge in the spacer; rhBMP-2, recombinant human bone morphogenetic protein-2. 
infiltrates were not consistently observed in rhBMP-2 samples. Furthermore, studies have reported that high doses of rhBMP-2 were associated with many lifethreatening complications, which can be traced and attributed to an inflammatory reaction. ${ }^{59}$

Some study limitations of the present study include the lack of long-term follow-up to determine whether the cystic voids persist, enlarge, or are replaced by new bone. Whether these findings are transient phenomena remains unknown. Using a larger number of animals with variable follow-up periods is recommended for further studies. At the same time, additional biochemical tests could aid in validating our FEA findings.

\section{Conclusions}

Although the use of rhBMP-2 effectively promotes lumbar fusion in sheep, the cystic changes to the bone brought about by rhBMP-2, especially in adjacent areas of the implants, were readily identifiable and compromised bone strength. The increased adipogenesis and osteoclastogenesis resulting from rhBMP-2 augmentation may be the primary cause of the cyst-like bone voids. Ultimately, physicians should remain aware of rhBMP-2's ability to produce cystlike bone void changes, even if the spine is successfully fused, and should carefully evaluate bony structural changes proximal to the implant.

\section{Acknowledgment}

K.T. is the guarantor of this work and, as such, had full access to all of the data in the study and takes responsibility for the integrity of the data and the accuracy of the data analysis.

\section{Supplemental Data}

Supplemental material for this article can be found at http://dx.doi.org/10.1016/j.ajpath.2017.03.010.

\section{References}

1. Burkus JK, Sandhu HS, Gornet MF, Longley MC: Use of rhBMP-2 in combination with structural cortical allografts: clinical and radiographic outcomes in anterior lumbar spinal surgery. J Bone Joint Surg Am 2005, 87:1205-1212

2. Mesfin A, Buchowski JM, Zebala LP, Bakhsh WR, Aronson AB, Fogelson JL, Hershman S, Kim HJ, Ahmad A, Bridwell KH: Highdose rhBMP-2 for adults: major and minor complications: a study of 502 spine cases. J Bone Joint Surg Am 2013, 95:1546-1553

3. Knox JB, Dai JM III, Orchowski J: Osteolysis in transforaminal lumbar interbody fusion with bone morphogenetic protein-2. Spine (Phila Pa 1976) 2011, 36:672-676

4. Garrett MP, Kakarla UK, Porter RW, Sonntag VK: Formation of painful seroma and edema after the use of recombinant human bone morphogenetic protein-2 in posterolateral lumbar spine fusions. Neurosurgery 2010, 66:1044-1049; discussion 1049
5. McClellan JW, Mulconrey DS, Forbes RJ, Fullmer N: Vertebral bone resorption after transforaminal lumbar interbody fusion with bone morphogenetic protein (rhBMP-2). J Spinal Disord Tech 2006, 19: 483-486

6. Rihn JA, Patel R, Makda J, Hong J, Anderson DG, Vaccaro AR, Hilibrand AS, Albert TJ: Complications associated with single-level transforaminal lumbar interbody fusion. Spine J 2009, 9:623-629

7. Brower RS, Vickroy NM: A case of psoas ossification from the use of BMP-2 for posterolateral fusion at L4-L5. Spine (Phila Pa 1976) 2008, 33:E653-E655

8. Muchow RD, Hsu WK, Anderson PA: Histopathologic inflammatory response induced by recombinant bone morphogenetic protein-2 causing radiculopathy after transforaminal lumbar interbody fusion. Spine J 2010, 10:e1-e6

9. Helgeson MD, Lehman RA Jr, Patzkowski JC, Dmitriev AE, Rosner MK, Mack AW: Adjacent vertebral body osteolysis with bone morphogenetic protein use in transforaminal lumbar interbody fusion. Spine J 2011, 11:507-510

10. Glassman SD, Hamill CL, Bridwell KH, Schwab FJ, Dimar JR, Lowe TG: The impact of perioperative complications on clinical outcome in adult deformity surgery. Spine (Phila Pa 1976) 2007, 32: 2764-2770

11. Fu R, Selph S, McDonagh M, Peterson K, Tiwari A, Chou R, Helfand M: Effectiveness and harms of recombinant human bone morphogenetic protein-2 in spine fusion: a systematic review and meta-analysis. Ann Intern Med 2013, 158:890-902

12. Wilke HJ, Kettler A, Claes LE: Are sheep spines a valid biomechanical model for human spines? Spine (Phila Pa 1976) 1997, 22 : $2365-2374$

13. Sandhu HS, Toth JM, Diwan AD, Seim HB III, Kanim LE, Kabo JM, Turner AS: Histologic evaluation of the efficacy of rhBMP-2 compared with autograft bone in sheep spinal anterior interbody fusion. Spine (Phila Pa 1976) 2002, 27:567-575

14. Lewandrowski KU, Nanson C, Calderon R: Vertebral osteolysis after posterior interbody lumbar fusion with recombinant human bone morphogenetic protein 2: a report of five cases. Spine J 2007, 7: 609-614

15. Siu RK, Lu SS, Li W, Whang J, McNeill G, Zhang X, Wu BM, Turner AS, Seim HB III, Hoang P, Wang JC, Gertzman AA, Ting K, Soo C: Nell-1 protein promotes bone formation in a sheep spinal fusion model. Tissue Eng Part A 2011, 17:1123-1135

16. Cowan CM, Jiang X, Hsu T, Soo C, Zhang B, Wang JZ, Kuroda S, Wu B, Zhang Z, Zhang X, Ting K: Synergistic effects of Nell-1 and BMP-2 on the osteogenic differentiation of myoblasts. J Bone Miner Res 2007, 22:918-930

17. Mulconrey DS, Bridwell KH, Flynn J, Cronen GA, Rose PS: Bone morphogenetic protein (RhBMP-2) as a substitute for iliac crest bone graft in multilevel adult spinal deformity surgery: minimum two-year evaluation of fusion. Spine (Phila Pa 1976) 2008, 33: 2153-2159

18. Baskin DS, Ryan P, Sonntag V, Westmark R, Widmayer MA: A prospective, randomized, controlled cervical fusion study using recombinant human bone morphogenetic protein-2 with the CORNERSTONE-SR allograft ring and the ATLANTIS anterior cervical plate. Spine (Phila Pa 1976) 2003, 28:1219-1224. discussion 1225

19. Boakye M, Mummaneni PV, Garrett M, Rodts G, Haid R: Anterior cervical discectomy and fusion involving a polyetheretherketone spacer and bone morphogenetic protein. J Neurosurg Spine 2005, 2: $521-525$

20. Boden SD, Kang J, Sandhu H, Heller JG: Use of recombinant human bone morphogenetic protein-2 to achieve posterolateral lumbar spine fusion in humans: a prospective, randomized clinical pilot trial: 2002 Volvo Award in clinical studies. Spine (Phila Pa 1976) 2002, 27: $2662-2673$

21. Burkus JK: Bone morphogenetic proteins in anterior lumbar interbody fusion: old techniques and new technologies. Invited 
submission from the Joint Section Meeting on Disorders of the Spine and Peripheral Nerves, March 2004. J Neurosurg Spine 2004, $1: 254-260$

22. Burkus JK, Heim SE, Gornet MF, Zdeblick TA: The effectiveness of rhBMP-2 in replacing autograft: an integrated analysis of three human spine studies. Orthopedics 2004, 27:723-728

23. Mummaneni PV, Pan J, Haid RW, Rodts GE: Contribution of recombinant human bone morphogenetic protein-2 to the rapid creation of interbody fusion when used in transforaminal lumbar interbody fusion: a preliminary report. Invited submission from the Joint Section Meeting on Disorders of the Spine and Peripheral Nerves, March 2004. J Neurosurg Spine 2004, 1: $19-23$

24. Poynton AR, Lane JM: Safety profile for the clinical use of bone morphogenetic proteins in the spine. Spine (Phila Pa 1976) 2002, 27: S40-S48

25. Sandhu HS, Khan SN: Recombinant human bone morphogenetic protein-2: use in spinal fusion applications. J Bone Joint Surg Am 2003, 85-A Suppl 3:89-95

26. Slosar PJ, Josey R, Reynolds J: Accelerating lumbar fusions by combining rhBMP-2 with allograft bone: a prospective analysis of interbody fusion rates and clinical outcomes. Spine J 2007, 7:301-307

27. Behrbalk E, Uri O, Parks RM, Musson R, Soh RC, Boszczyk BM: Fusion and subsidence rate of stand alone anterior lumbar interbody fusion using PEEK cage with recombinant human bone morphogenetic protein-2. Eur Spine J 2013, 22:2869-2875

28. Frenkel MB, Cahill KS, Javahary RJ, Zacur G, Green BA, Levi AD: Fusion rates in multilevel, instrumented anterior cervical fusion for degenerative disease with and without the use of bone morphogenetic protein. J Neurosurg Spine 2013, 18:269-273

29. Hamilton DK, Smith JS, Reames DL, Williams BJ, Chernavvsky DR, Shaffrey CI: Safety, efficacy, and dosing of recombinant human bone morphogenetic protein-2 for posterior cervical and cervicothoracic instrumented fusion with a minimum 2-year follow-up. Neurosurgery 2011, 69:103-111; discussion 111

30. Dorward IG, Buchowski JM, Stoker GE, Zebala LP: Posterior cervical fusion with recombinant human bone morphogenetic protein-2: complications and fusion rate at minimum 2-year follow-up. Clin Spine Surg 2016, 29:E276-E281

31. Hiremath GK, Steinmetz MP, Krishnaney AA: Is it safe to use recombinant human bone morphogenetic protein in posterior cervical fusion? Spine (Phila Pa 1976) 2009, 34:885-889

32. Lee KB, Taghavi CE, Hsu MS, Song KJ, Yoo JH, Keorochana G, Ngo SS, Wang JC: The efficacy of rhBMP-2 versus autograft for posterolateral lumbar spine fusion in elderly patients. Eur Spine J 2010, 19:924-930

33. Hurlbert RJ, Alexander D, Bailey S, Mahood J, Abraham E, McBroom R, Jodoin A, Fisher C: rhBMP-2 for posterolateral instrumented lumbar fusion: a multicenter prospective randomized controlled trial. Spine (Phila Pa 1976) 2013, 38:2139-2148

34. Mannion RJ, Nowitzke AM, Wood MJ: Promoting fusion in minimally invasive lumbar interbody stabilization with low-dose bone morphogenic protein-2-but what is the cost? Spine J 2011, 11: $527-533$

35. Singh K, Nandyala SV, Marquez-Lara A, Cha TD, Khan SN, Fineberg SJ, Pelton MA: Clinical sequelae after rhBMP-2 use in a minimally invasive transforaminal lumbar interbody fusion. Spine J 2013, 13:1118-1125

36. Morimoto T, Kaito T, Kashii M, Matsuo Y, Sugiura T, Iwasaki M, Yoshikawa H: Effect of intermittent administration of teriparatide (parathyroid hormone 1-34) on bone morphogenetic protein-induced bone formation in a rat model of spinal fusion. J Bone Joint Surg Am 2014, 96:e107

37. Fischgrund JS, James SB, Chabot MC, Hankin R, Herkowitz HN, Wozney JM, Shirkhoda A: Augmentation of autograft using rhBMP2 and different carrier media in the canine spinal fusion model. J Spinal Disord 1997, 10:467-472
38. Seeherman HJ, Li XJ, Bouxsein ML, Wozney JM: rhBMP-2 induces transient bone resorption followed by bone formation in a nonhuman primate core-defect model. J Bone Joint Surg Am 2010, 92:411-426

39. Zarrinkalam MR, Schultz CG, Ardern DW, Vernon-Roberts B, Moore RJ: Recombinant human bone morphogenetic protein-type 2 (rhBMP-2) enhances local bone formation in the lumbar spine of osteoporotic sheep. J Orthop Res 2013, 31:1390-1397

40. Sampath TK, Muthukumaran N, Reddi AH: Isolation of osteogenin, an extracellular matrix-associated, bone-inductive protein, by heparin affinity chromatography. Proc Natl Acad Sci U S A 1987, 84: 7109-7113

41. Wang EA, Rosen V, Cordes P, Hewick RM, Kriz MJ, Luxenberg DP, Sibley BS, Wozney JM: Purification and characterization of other distinct bone-inducing factors. Proc Natl Acad Sci U S A 1988, 85: 9484-9488

42. Shields LB, Raque GH, Glassman SD, Campbell M, Vitaz T, Harpring J, Shields CB: Adverse effects associated with highdose recombinant human bone morphogenetic protein-2 use in anterior cervical spine fusion. Spine (Phila $\mathrm{Pa}$ 1976) 2006, 31: $542-547$

43. Kaneko H, Arakawa T, Mano H, Kaneda T, Ogasawara A, Nakagawa M, Toyama Y, Yabe Y, Kumegawa M, Hakeda Y: Direct stimulation of osteoclastic bone resorption by bone morphogenetic protein (BMP)-2 and expression of BMP receptors in mature osteoclasts. Bone 2000, 27:479-486

44. Smucker JD, Rhee JM, Singh K, Yoon ST, Heller JG: Increased swelling complications associated with off-label usage of rhBMP-2 in the anterior cervical spine. Spine (Phila Pa 1976) 2006, 31: 2813-2819

45. Wong DA, Kumar A, Jatana S, Ghiselli G, Wong K: Neurologic impairment from ectopic bone in the lumbar canal: a potential complication of off-label PLIF/TLIF use of bone morphogenetic protein-2 (BMP-2). Spine J 2008, 8:1011-1018

46. Peyrin F, Salome M, Cloetens P, Laval-Jeantet AM, Ritman E, Ruegsegger P: Micro-CT examinations of trabecular bone samples at different resolutions: 14, 7 and 2 micron level. Technol Health Care 1998, 6:391-401

47. Benglis D, Wang MY, Levi AD: A comprehensive review of the safety profile of bone morphogenetic protein in spine surgery. Neurosurgery 2008, 62(5 Suppl 2):ONS423-ONS431; discussion ONS431

48. Burkus JK, Dorchak JD, Sanders DL: Radiographic assessment of interbody fusion using recombinant human bone morphogenetic protein type 2. Spine (Phila Pa 1976) 2003, 28:372-377

49. McKay B, Sandhu HS: Use of recombinant human bone morphogenetic protein-2 in spinal fusion applications. Spine (Phila Pa 1976) 2002, 27:S66-S85

50. Mimatsu K, Kishi S, Hashizume Y: Experimental chronic compression on the spinal cord of the rabbit by ectopic bone formation in the ligamentum flavum with bone morphogenetic protein. Spinal Cord 1997, 35:740-746

51. Mroz TE, Wang JC, Hashimoto R, Norvell DC: Complications related to osteobiologics use in spine surgery: a systematic review. Spine (Phila Pa 1976) 2010, 35:S86-S104

52. Jensen ED, Pham L, Billington CJ Jr, Espe K, Carlson AE, Westendorf JJ, Petryk A, Gopalakrishnan R, Mansky K: Bone morphogenic protein 2 directly enhances differentiation of murine osteoclast precursors. J Cell Biochem 2010, 109(4):672-682

53. Zhang H, Schulz TJ, Espinoza DO, Huang TL, Emanuelli B, Kristiansen K, Tseng YH: Cross talk between insulin and bone morphogenetic protein signaling systems in brown adipogenesis. Mol Cell Biol 2010, 30:4224-4233

54. Zara JN, Siu RK, Zhang X, Shen J, Ngo R, Lee M, Li W, Chiang M, Chung J, Kwak J, Wu BM, Ting K, Soo C: High doses of bone morphogenetic protein 2 induce structurally abnormal bone and inflammation in vivo. Tissue Eng Part A 2011, 17:1389-1399 
55. Lee KB, Taghavi CE, Song KJ, Sintuu C, Yoo JH, Keorochana G, Tzeng ST, Fei Z, Liao JC, Wang JC: Inflammatory characteristics of rhBMP-2 in vitro and in an in vivo rodent model. Spine (Phila Pa 1976) 2011, 36:E149-E154

56. Marusic A, Grcevic D, Katavic V, Kovacic N, Lukic IK, Kalajzic I, Lorenzo JA: Role of B lymphocytes in new bone formation. Lab Invest 2000, 80:1761-1774

57. Marusic A, Katavic V, Grcevic D, Lukic IK: Genetic variability of new bone induction in mice. Bone 1999, 25:25-32
58. Choudhry OJ, Christiano LD, Singh R, Golden BM, Liu JK: Bone morphogenetic protein-induced inflammatory cyst formation after lumbar fusion causing nerve root compression. J Neurosurg Spine 2012, 16:296-301

59. Crawford CH III, Carreon LY, McGinnis MD, Campbell MJ, Glassman SD: Perioperative complications of recombinant human bone morphogenetic protein-2 on an absorbable collagen sponge versus iliac crest bone graft for posterior cervical arthrodesis. Spine (Phila Pa 1976) 2009, 34:1390-1394 